\title{
CLIMATE CHANGE IMPACTS AND WATER RESOURCES MANAGEMENT: CHEHEL-CHAI BASIN, IRAN
}

\author{
SHAKIB, H. S. ${ }^{1}$ - SHOJARASTEGARI, H. ${ }^{2 *}$ \\ ${ }^{1}$ Faculty of Civil Engineering, Bozorgmehr University of Qaenat \\ South Khorasan, Qaen, Iran \\ (e-mail: hshakib@buqaen.ac.ir; phone: +98-5-632-560-491; fax: +98-5-632-526-530) \\ ${ }^{2}$ Young Elite Sponsors Institution \\ South Khorasan, Qaen, Iran \\ *Corresponding author \\ e-mail:hamidshojarastegari@yahoo.com \\ phone: +98-5-632-521-181; fax: +98-5-632-526-530 \\ (Received 22 ${ }^{\text {nd }}$ Feb 2017; accepted $1^{\text {st }}$ Aug 2017)
}

\begin{abstract}
This study focuses on the impacts of climate changes by applying a conventional general circulation model (HadCM3) to report the output subscale of LARS-WG using HadCM3 statistical model. We have used SWAT model to study the changes in the runoff volumes of the Chehel-Chai basin. The study results suggest regardless of the occurrence of each of the three future rounds, the temperature would rise causing an increase in rainfall. This would cause a decrease in the rate of flow of Chehel-Chai River. An increase in evaporation, transpiration, and discharge of the river water for irrigation would subsequently reduce the flow rate of the Chehel-Chai River.
\end{abstract}

Keywords: HadCM3 model, statistical models LARS-WG, SWAT

\section{Introduction}

Climate changes are known to cause alteration in the duration, intensity, form, and timing of rainfall in many areas. Consequently, droughts and flooding would be immanent in the nearby areas. On the other hand, water resource management programs have been affected by the rapid climate changes more often in the recent years. Since 1995 numerous research and modeling studies have focused on forecasting the impacts of rapid climate changes on water resource plans. As large-scale global climate models are based on the defined networks (150 to $300 \mathrm{~km}$ ) they would not be applied directly to assess the hydrological models.

Among a few detailed models one might identify the Atmospheric-ocean general circulation models coupled type (AOGCM). The model is designed and developed at the Hadley Centre, UK. The resolution of this model is 2.75 by 3.75 degrees (IPCC, 2007). The model is described by (Gordon et al., 2000; Pope et al., 2000). HadCM3 consists of two components, namely Oceanic and Atmospheric HadAM3 (atmospheric model) and HadOM3 (the ocean), which has an ice-sea model. This model requires the setting surface flux. Based on a calendar year (365 days and 30 days of month) this model has a high resolution oceanic components. Another advantage of this model is its good coordination between the atmosphere and the ocean.

Steele-Dunne et al. (2008) examined impact of climate change on the hydrology of river flow using ECHAM 5 general circulation models and emission scenarios A1B. By application of the conceptual rainfall-runoff model HBV-Light, they were able to evaluate the future river flow on 9 basins located in Ireland. Varanou et al. (2003) 
examined changes of quantity and quality of runoff in a basin in central Greece using SWAT model to show the reduction of flow as well as the increase of the nitrogen concentration.

As Yu et al. (2002), Chen et al. (2011) and Dhar and Mazumdar (2009) show the effect of climate change on water resources would be an increase in temperature for prolonged periods of time along with the impact of the increased $\mathrm{CO}_{2}$ on the river runoff volumes in several regions drastic changes in daily rainfall;

Studies elsewhere have shown that rapid climate changes would also impact plant growth, irrigation time, and runoff volumes (Ficklin et al., 2009).

In a study in Taiwan Lin et al. (2010) developed an annual warning indicator to assess the impact of climate change on water resources. The study shows the annual changes impose significant impacts on the ground water system by changing the temperature, precipitation, as well as other variables such as evapotranspiration.

Koutroulis et al. (2013) studied the impact of climate change on a regional Greek water resource. They have concluded that owed it is necessary to improve and update local water management planning and adaptation strategies in order to secure future water supplies.

Nkhonjera (2017) provided a review about Understanding the impact of climate change on the dwindling water resources of South Africa. In general, the factors such as lack of political will, climate modelling constraints, and uncertainties in both climate and hydrological modelling are of particular importance that they feature highly in climate change impact analysis studies. Results showed diversity in climate model simulations should be seen as a positive attribute and a judicious selection, configuration, and calibration of these hydrological models need to reduce uncertainties in hydrological modeling.

Inouye et al. (2017) assessed parameters of Climate Impacts on water Resources in Idaho. A new scenario was developed to assess the range of impacts by developing a model of the river basin and two another quantitative models (a system dynamics model and a spatially-explicit integrated model) in order to explore research.

Seiller et al. (2017) studied the Influence of three common calibration metrics on the diagnosis of climate change impacts on water resource. In that investigation, based on thirty-seven Canadian catchments, three common objective functions (focusing on different sections of time series), and twelve lumped conceptual hydrologic models, aim to provide insight on this specific contribution to the uncertainty cascade. Results from this study show that the choice of an objective function, between pairs of common options, can clearly affect our interpretation of the impacts of climate change on water resources. Furthermore, these conclusions are dependent on the hydrologic model, illustrating the need for water managers to evaluate their operated model and studied catchments to appraise the predictability of their hydrological system and estimate their confidence level.

Nepal (2016) assessed the Impacts of climate change on the hydrological regime of the Koshi River. The results suggested that snowfall pattern, snowmelt, total discharge, and evapotranspiration are all sensitive to climate change. The results should be taken as indicative of how the hydrological regime might change in future rather than definitive. By incorporating high resolution data and replicating studies in reference catchments in the Himalayan region, analyses of this type can be made more reliable. 


\section{The Study Area}

The Chehel-Chai basin, with an area of 25.683 hectares is located at the $55^{\circ} 23-55^{\circ}$ $38^{\prime}$ longitude and $36^{\circ} 59^{\prime}-37^{\circ} 13^{\prime}$ latitude. As a subdivision of the great Gorganrood basin, this basin is located within the city boundary of Minoodasht in Golestan Province and has a minimum and maximum elevation of $190 \mathrm{~m}$ and $2570 \mathrm{~m}$ above the sea level. Fig. 1 shows the location of Chehel-Chai basin.

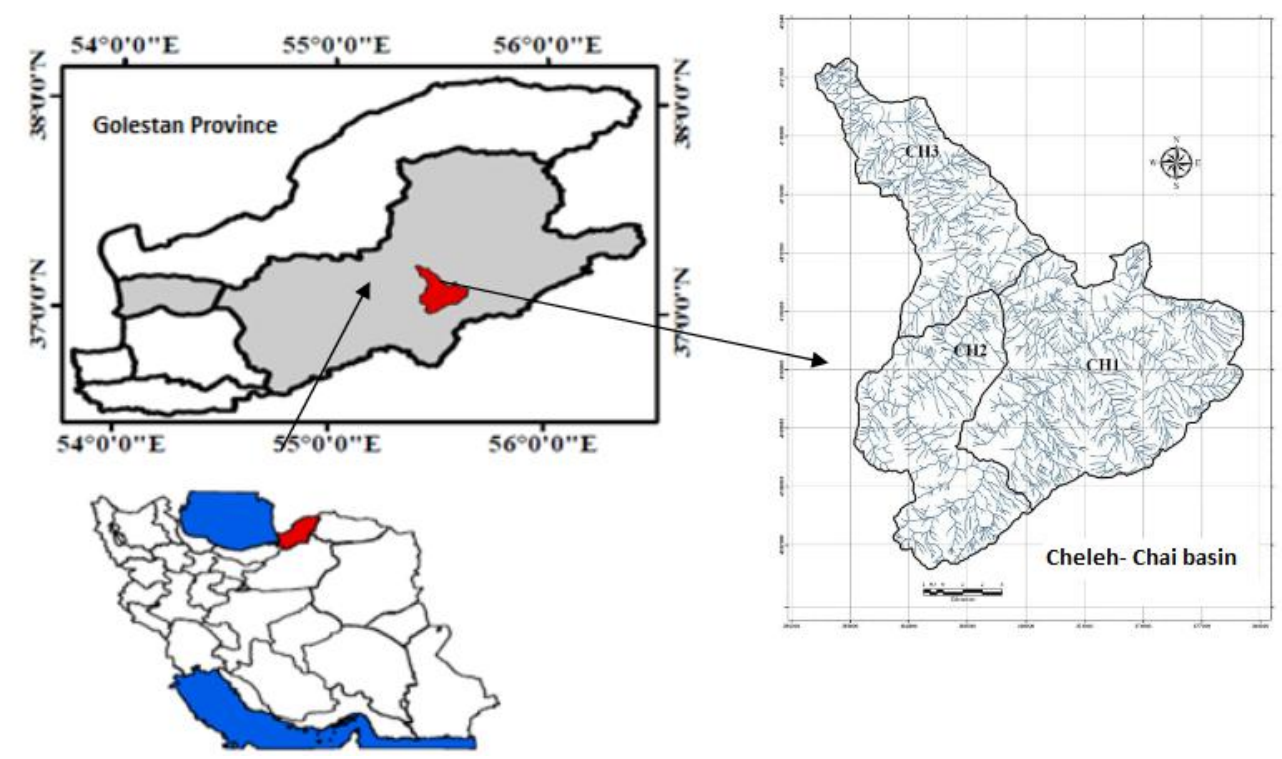

Figure 1. Location map of Chehel-Chai basin in Golestan Province of Iran

\section{The Model}

In order to gather the runoff data of the study area as one of the main inputs of the model, we used the DEM map, the land use map, and the soil map, (Figs. 2-4 respectively).The meteorological data was collected and prepared in ArcGIS 10.3 for entry into the model. We used also the moisture content, saturated hydraulic conductivity, and soil bulk density based on the available data. The CROPWAT data were obtained using the available database of the soil texture.

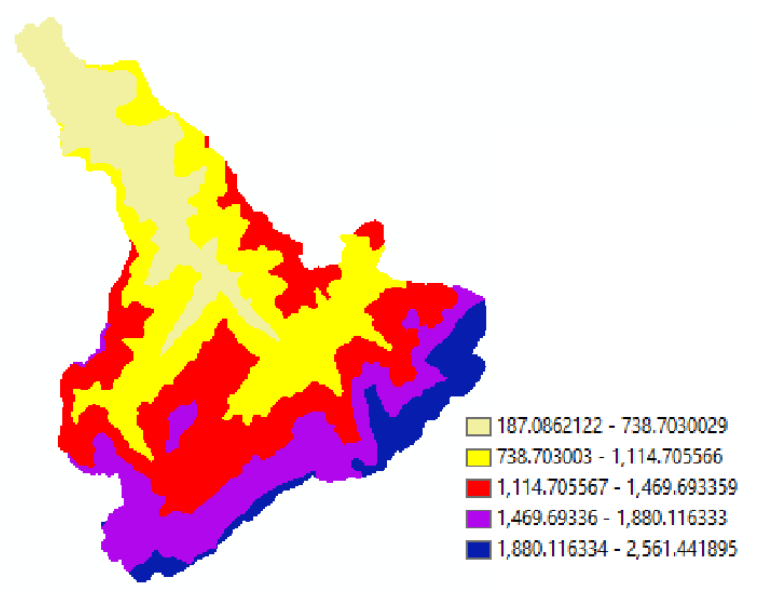

Figure 2. Map of digital elevation model (DEM) at Chehel-Chai basin 


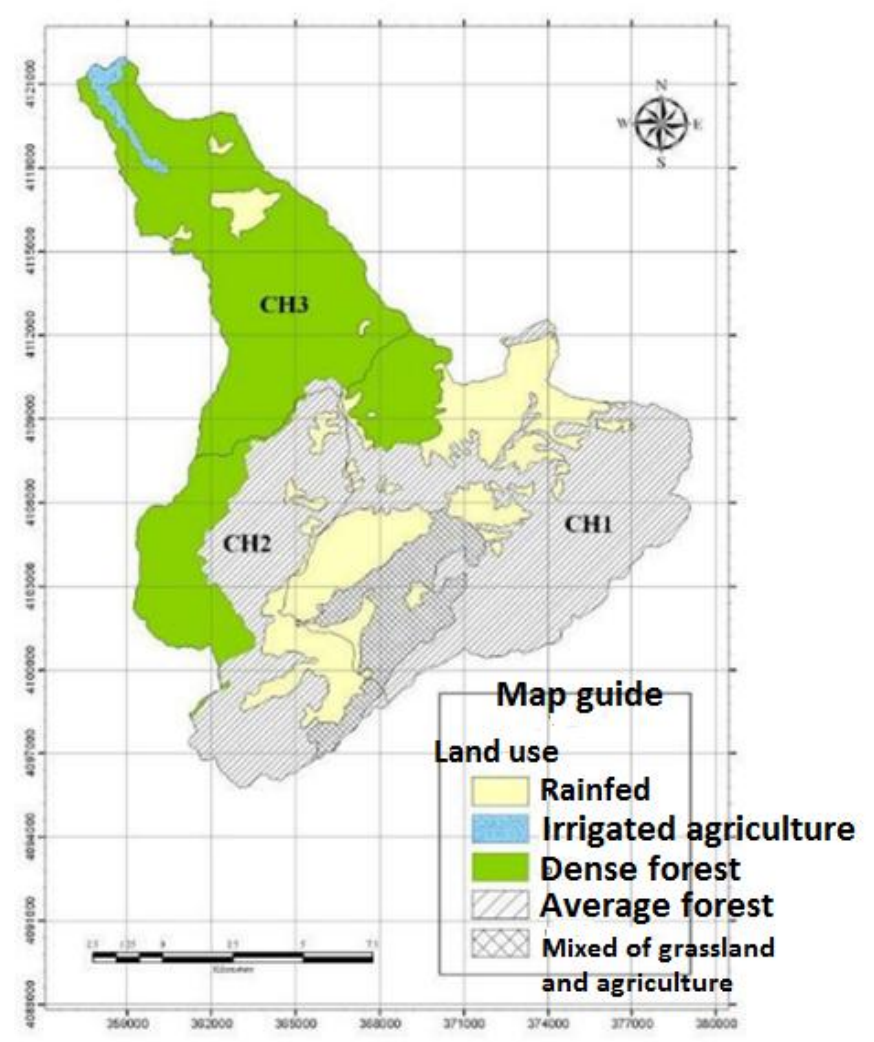

Figure 3. Land use map of Chehel-Chai basin

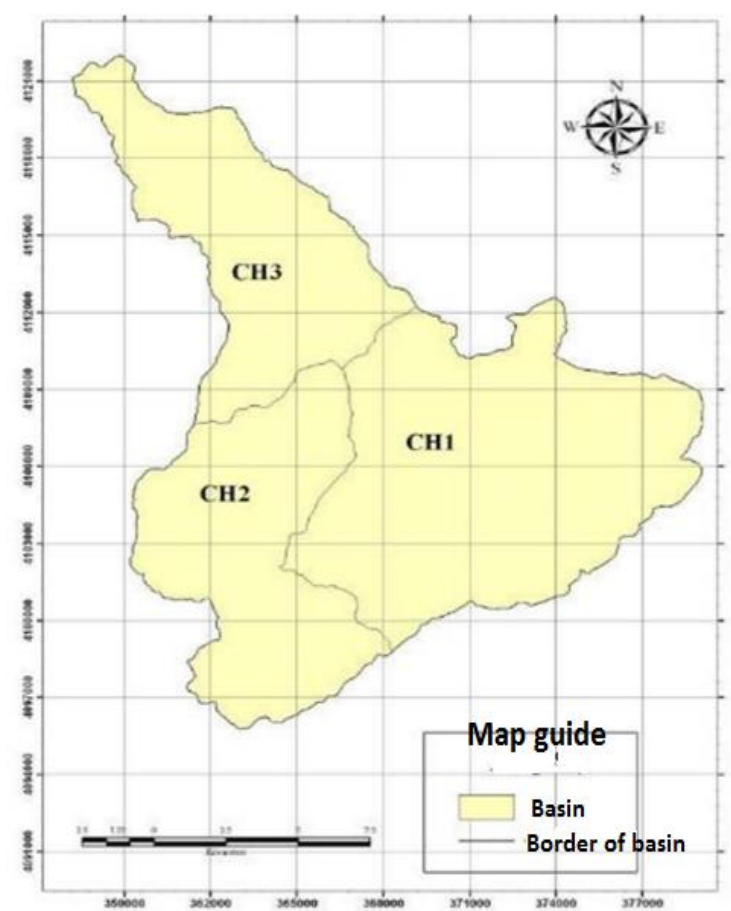

Figure 4. Map of soil hydrological groups of Chehel-Chai basin 
The minimum and maximum monthly temperature ranges of the study area are provided in Figs. 5 and 6 respectively. Table 1 shows other physiographic parameters used in the model.

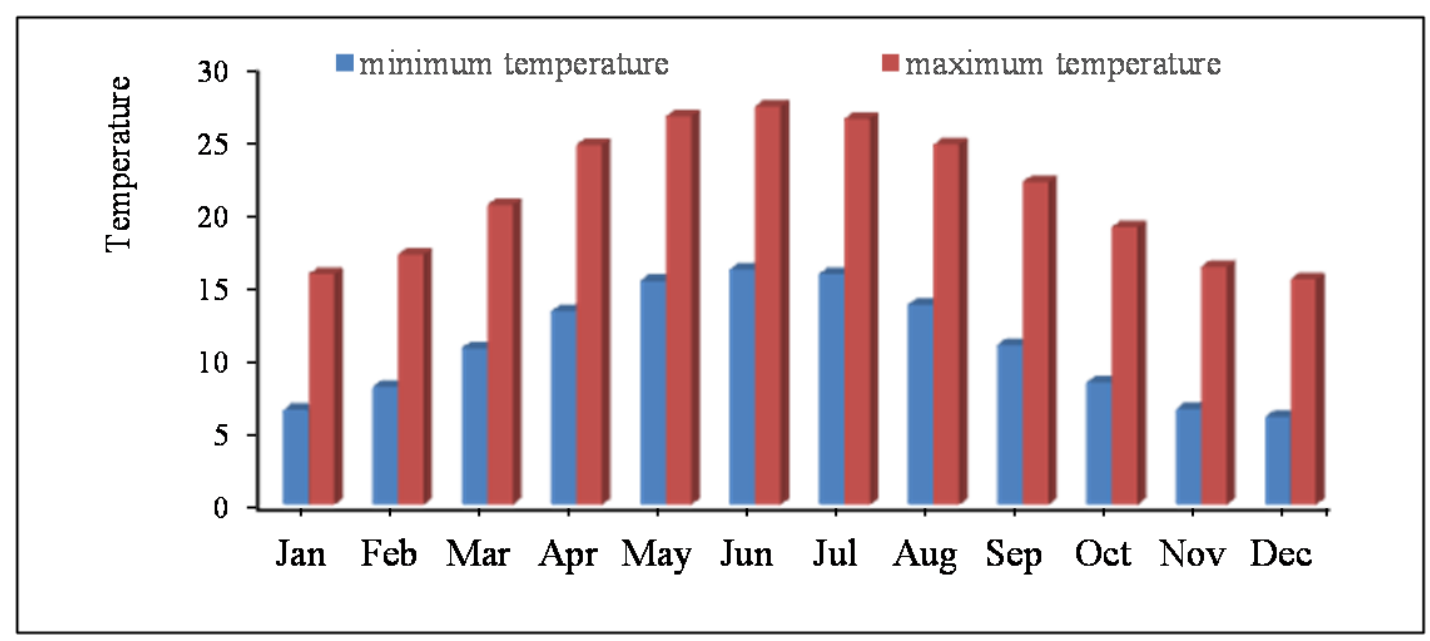

Figure 5. The minimum and maximum air temperature at Chehel-Chai evaporation measuring stations

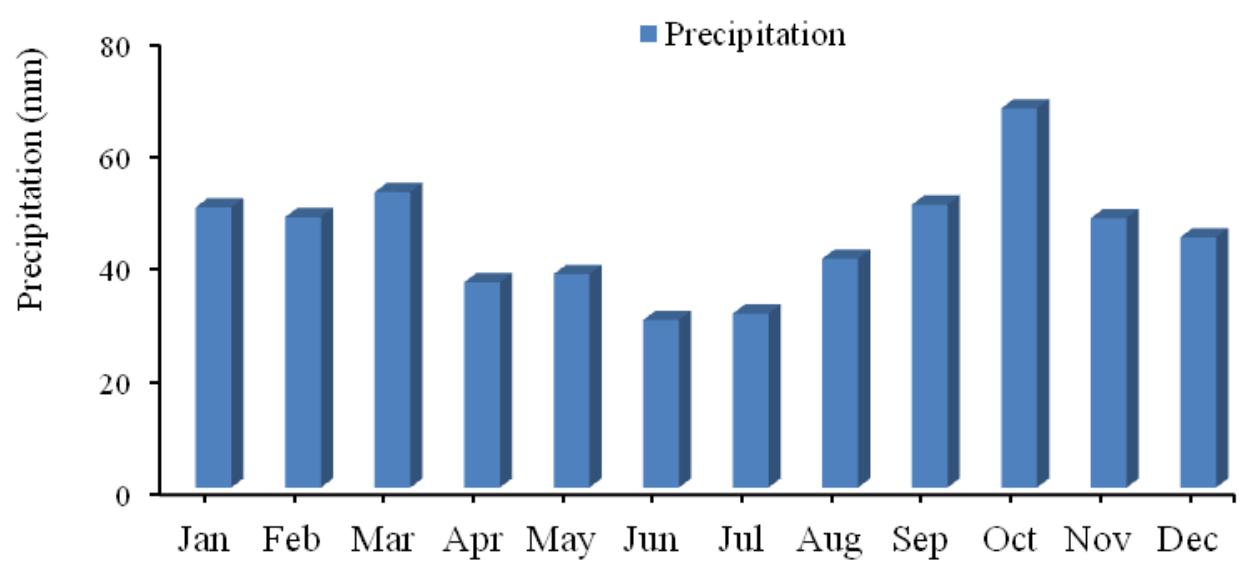

Figure 6. monthly precipitation of Chehel-Chai evaporation measuring stations

Table 1. Chehel-Chai sub-basins physiographic characteristics

\begin{tabular}{c|c|c|c|c|c}
\hline Row & Sub-basin & Area & Perimeter & Weighted & Weighted \\
\hline 1 & CH1 & 118.82 & 53.89 & 46.89 & 1388.80 \\
2 & CH2 & 71.26 & 45.99 & 42.88 & 1327.31 \\
3 & CH3 & 66.75 & 46.19 & 47.06 & 713.56 \\
\hline \multicolumn{2}{r|}{ Total } & 256.83 & 95.24 & 45.82 & 951.14 \\
\hline
\end{tabular}




\section{HadCM3 Climate models}

In statistical method of determining optimal function, large-scale climate variables have been simulated by general circulation models in future periods, these functions are applied as input variables in the surface. In this method, a statistical relationship using simple regression, multivariate, neural networks and stations between actual behavior and general circulation model output is generated. After verification, these equations can be used in downscaling projections of future emission scenarios. In this study, in order to study climate change from a traditional to HadCM3 general circulation models and downscaling to weather generator LARS-WG statistical model was used.

LARS-WG for simulation of wet and dry periods, rainfall and solar radiation, distribution of the quasi-experimental uses the following form:

$$
E P M=\left\{a_{0}, a_{i}, h_{i}, i=1, \ldots, 10\right\}
$$

That histogram consists of 10 floors and each floor is defined in $\left[a_{i-1}, a_{i}\right)$ ed, so $a_{i-1}<a_{i}$ and $h_{i}$ frequency of observed phenomena, $i t h$ is on the floor. In this research initially to calibrate and verify models and scenarios, the criteria NSE, RMSE and R2 were used. Followings are the relations for the presented criteria:

$$
\begin{aligned}
& N S E=1-\frac{\sum_{i=1}^{N}\left(o_{i}-S_{i}\right)^{2}}{\sum_{i=1}^{N}\left(o_{i}-\bar{o}\right)^{2}} \\
& R M S E=\left[\frac{1}{N} \sum_{i=1}^{N}\left(S_{i}-O_{i}\right)\right]^{1 / 2} \\
& R^{2}=\left[\frac{\frac{1}{n} \sum_{m=1}^{n}\left(S_{i}-S\right)\left(o_{i}-\sigma\right)}{\sigma_{s} \times \sigma_{0}}\right]^{2}
\end{aligned}
$$

where: $\mathrm{O}_{\mathrm{i}}$ : observational data, $\mathrm{S}_{\mathrm{i}}$ : Estimated data, $\overline{\mathbf{0}}$ and $\overline{\mathbf{S}}$ observed data and estimated mean, $\sigma$ is the variance.

First, LARS-WG model was calibrated for the base period 1982-2010, and then by restarting the calibrated model, the validation was used for the base period. The results of calibration and verification data and the observed small-scale temperature and precipitation are presented in Table 2. According to Nash-Sutcliffe coefficient of determination and capability indices, the model has a good capability in down-scaling the regional temperature data and the region precipitation in future periods. After securing the model simulation results, the maximum temperature variables (Fig. 7) and minimal (Fig. 8) and precipitation (Fig. 9) by HADCM3 model for future periods from 2011 to 2030, 2046 to 2065 and 2080 to 2099 during climate scenarios SRA1B, SRA2 and SAB1 were predicted.

Table 2. Statistics error of climate parameters observed and modeled by model LARS-WG

\begin{tabular}{c|c|c|c|c|c|c|c|c|c}
\hline \multicolumn{2}{c|}{$\begin{array}{c}\text { Monthly maximum } \\
\text { temperature average }\end{array}$} & \multicolumn{3}{c|}{$\begin{array}{c}\text { Monthly minimum } \\
\text { temperature average }\end{array}$} & \multicolumn{3}{c|}{$\begin{array}{c}\text { Monthly average } \\
\text { precipitation }\end{array}$} & Period \\
\hline $\mathrm{R}^{2}$ & $\mathrm{RMSE}$ & $\mathrm{NSE}$ & $\mathrm{R}^{2}$ & $\mathrm{RMSE}$ & $\mathrm{NSE}$ & $\mathrm{R}^{2}$ & $\mathrm{RMSE}$ & $\mathrm{NSE}$ & \\
0.99 & 0.49 & 0.99 & 0.99 & 0.38 & 0.99 & 0.88 & 5.2 & 0.80 & Validation \\
0.99 & 0.54 & 0.98 & 0.99 & 0.43 & 0.99 & 0.79 & 6.8 & 0.73 & Calibration \\
\hline
\end{tabular}




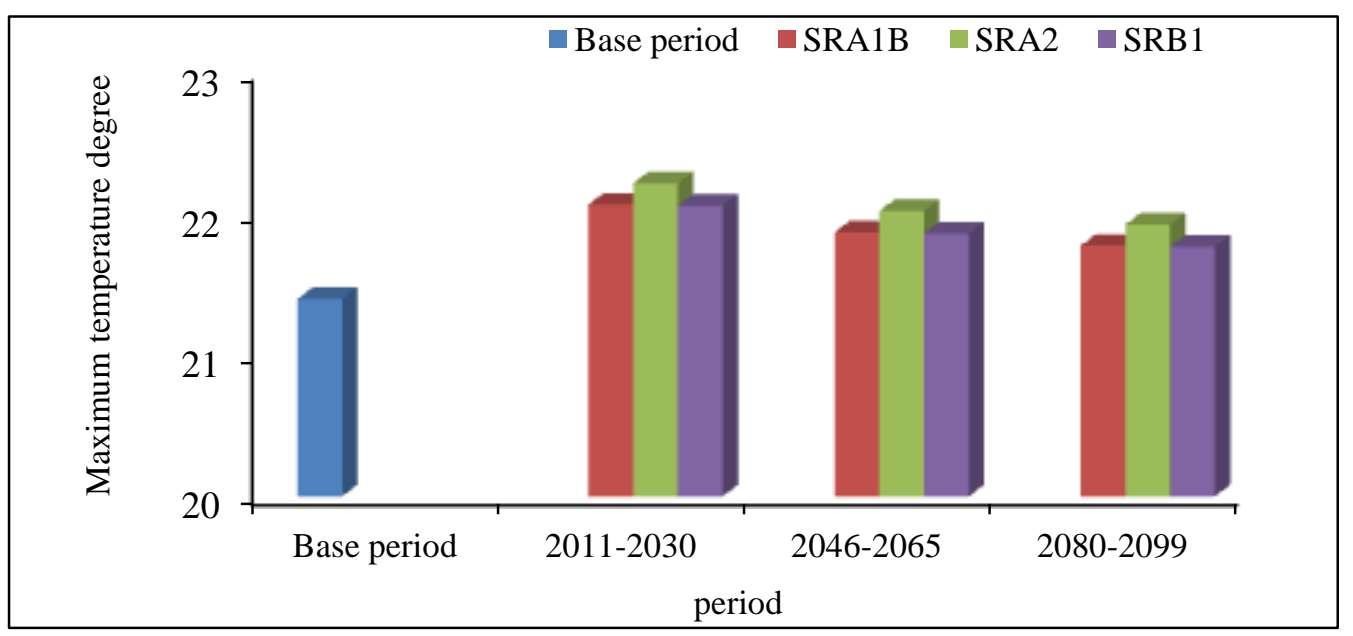

Figure 7. Long-term average annual maximum temperature for the base period and future

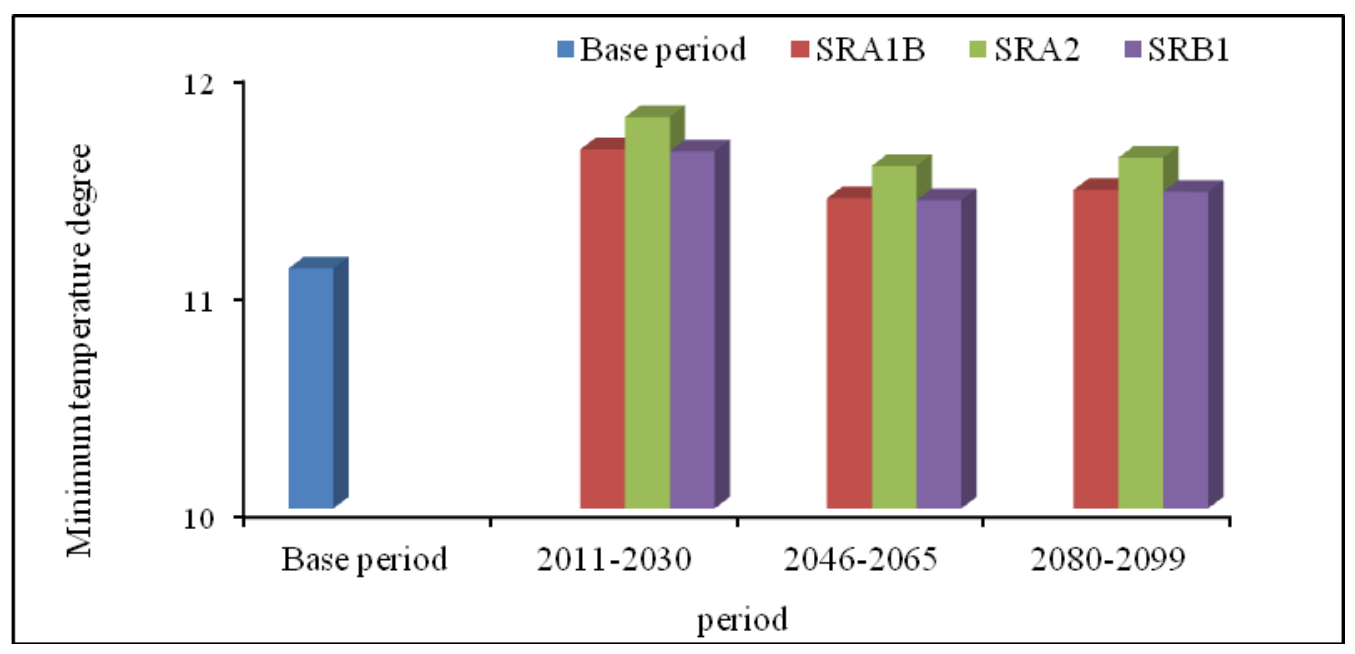

Figure 8. Long-term average annual minimum temperature for the base period and future periods

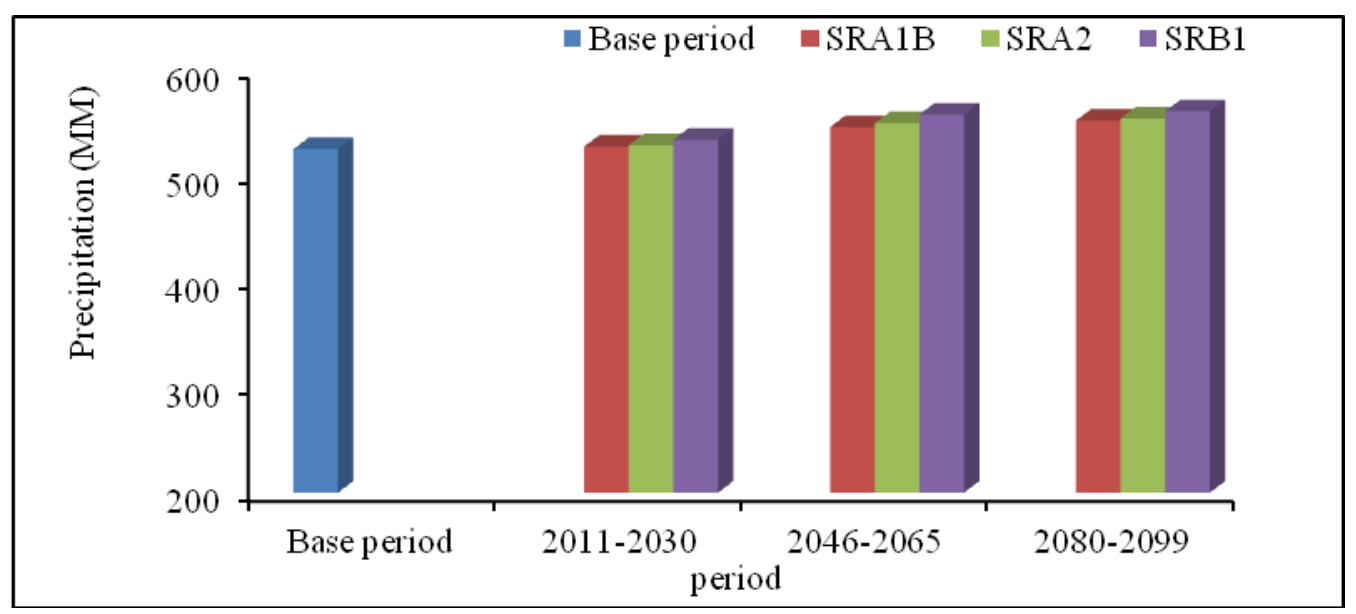

Figure 9. The long-term average annual precipitation for the base period and future periods 
By comparing the average values of the maximum temperature specified in Fig. 7 it is obvious that the maximum temperature in all three rounds will be higher than the base period. (Rise in temperature to 0.82 degrees' Celsius maximum temperature 0.37 ) In all three scenarios the highest maximum temperature will occur in 2011-2030 period, however, for future periods, during the period 2080-2099 all three scenarios are lower than the maximum temperature will be two periods of 2011-2030 and 2046-2065.

In Fig. 8, the minimum temperature in all three rounds will be higher than the base period. ( 0.31 to 0.70 degrees' Celsius rise in temperature, at least) In all three scenarios the maximum temperature will occur at least in the period 2011-2030, however, for future periods, during the period 2046-2065 all three scenarios are lower than the minimum temperature in two periods 2011-2030 and 2080-2099.

In Fig. 9 by comparing the average values of rainfall it is clear that precipitation in all three rounds will be higher than the base period (Increased precipitation between 2.34 to $35.89 \mathrm{~mm}$ ) and rainfall amounts will increase over time. In all three scenarios, the most precipitation will occur over the period 2080-2099, however, for future periods, during the period 2011-2030 all three scenarios are less than two periods 20462065 and 2080-2099.

\section{Flow simulation using the SWAT}

SWAT distribution model was used to assess the impact of climate change on hydrology of Chehel-Chai basin. This model is sensitive to changes of Earth and climate. Hydrological cycle, which in this simulation model is based on water balance equation is as follows:

$$
\mathrm{SWt}=S W o+\sum_{i=1}^{t}(R d a y-Q \operatorname{surf}-E a-W \operatorname{seep}-Q g w)
$$

In this regard $\mathrm{SW}_{\mathrm{t}}$ is final amount of water in the soil (mm), $\mathrm{t}$ - time (days), $\mathrm{SW}_{\mathrm{o}}$ - the amount of water in the soil $(\mathrm{mm}), \mathrm{R}_{\text {day }^{-}}$amount of precipitation in day $\mathrm{i}(\mathrm{mm}), \mathrm{Q}_{\text {surf- }}{ }^{-}$ amount of surface runoff in day $\mathrm{i}(\mathrm{mm}), \mathrm{E}_{\mathrm{a}^{-}}$evapotranspiration in day $\mathrm{i}(\mathrm{mm}), \mathrm{W}_{\text {seep}^{-}}$ amount of water in the soil profile penetrated in the cortical area $(\mathrm{mm})$ and $\mathrm{Q}_{\mathrm{gw}^{-}}$flow back in the day $\mathrm{i}(\mathrm{mm})$

In this regard, after the gathering and preparation of needed meteorological data and maps, according to the initial values of the parameters, SWAT continuous rainfallrunoff model for the base period of the years 1982-2010 was calibrated and validated. Additional SWAT CUP was used for model calibration software. During the study period to simulate the runoff of years (2000-1982) to calibrate the model and year period (2010-2001) were selected for validation period. Then, the effects of climate change and global warming on the hydrological basin in future periods were evaluated.

In simulation using the model it is necessary to indicate the parameters that output of the model shows the most sensitivity and for the calibration of the model, the sensitive parameter should only be used. For this purpose, after the initial implementation of the model to analyze the sensitivity of the effect of various parameters on model outputs was based on objective function of Nash-Sutcliffe.

This software with the observed data and parameters to modify, the changes range for each parameter identified and covered most of the measured data, the minimum thickness of the strip uncertainties may follow. Table 3 shows the results of a sensitivity analysis to calibrate and validate in SWAT CUP. Also performance evaluation model 
using coefficients R2, NS, RMSE, P-factor and R-factor between observed and simulated data was performed (Table 4).

Table 3. Optimal values of the parameters studied for runoff simulation with the range of parameter values.

\begin{tabular}{c|c|c|c|c}
\hline Maximum & Minimum & $\begin{array}{c}\text { Optimal } \\
\text { value }\end{array}$ & Name of parameter & Row \\
\hline 1.01 & 0.27 & 0.83 & R_CN2.mgt & 1 \\
116.47 & 58.71 & 93.74 & V_CANMX.hru & 1 \\
0.65 & 0.34 & 0.58 & V__ESCO.hru & 3 \\
0.25 & -0.25 & 0 & V__ALPHA_BNK.rte & 4 \\
1.25 & 0.69 & 0.74 & R__HRU_SLP.hru & 5 \\
9.79 & 2.47 & 2.72 & V__SFTMP.bsn & 6 \\
0.31 & -3.42 & 0.02 & V__SMTMP.bsn & 7 \\
49.64 & 3.55 & 24.82 & R__LAPS.sub & 8 \\
0.14 & 0.02 & 0.05 & V_GW_REVAP.gw & 9 \\
0.46 & 0.06 & 0.20 & V__RCHRG_DP.gw & 10 \\
\hline
\end{tabular}

Table 4. The resulting coefficient for calibration of the model to simulate runoff monthly

\begin{tabular}{c|c|c|c|c}
\hline R-factor & P-factor & RMSE & NS & $\mathbf{R}^{\mathbf{2}}$ \\
\hline 1.07 & 0.84 & 0.175 & 0.66 & 0.71 \\
\hline
\end{tabular}

Fig. 10 shows simulated and observed values with 95\% confidence interval for calibration periods. According to the results of the calibration, the model has a good ability to simulate water flow in the time period.

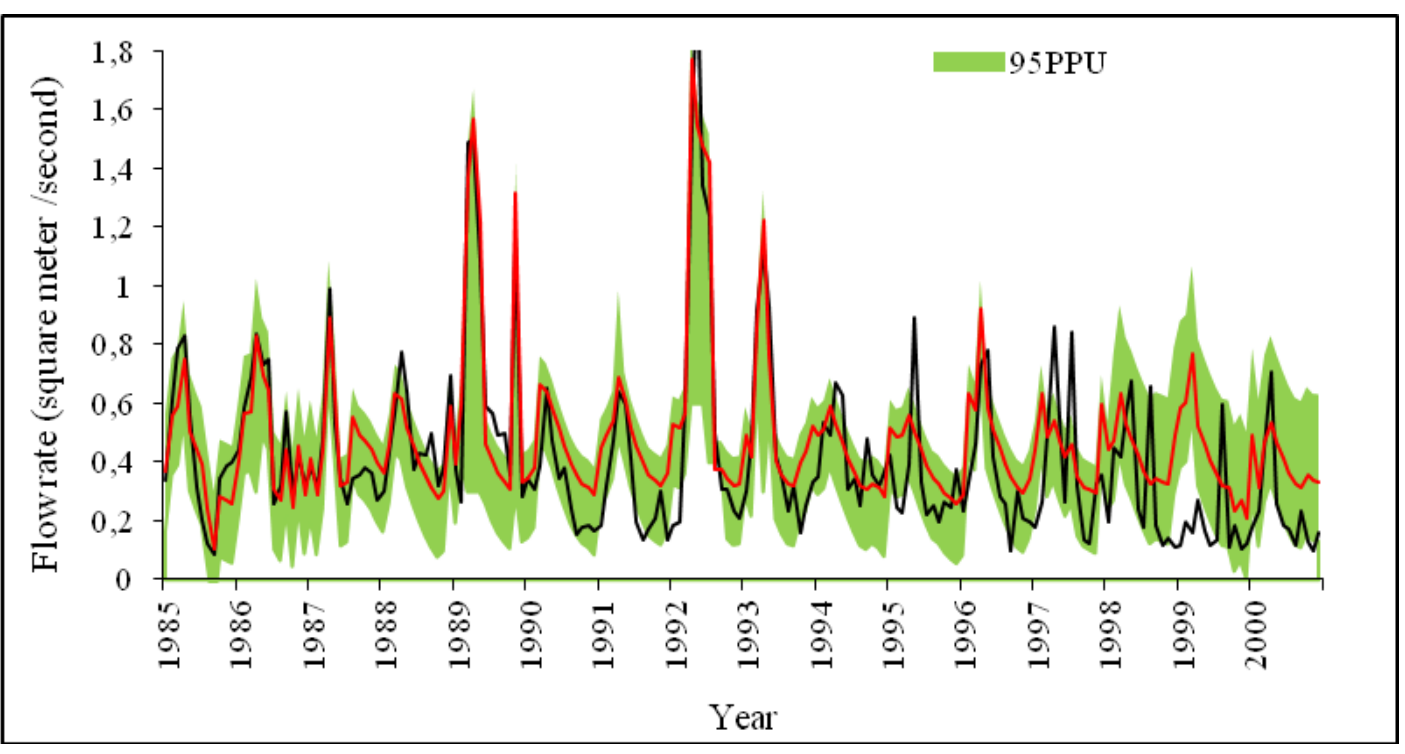

Figure 10. Simulated and observed values with the confidence interval for calibration periods 
In the calibration, results in $95 \%$ confidence level for the validation process is shown in Fig. 11. Amounts related to the accuracy of model is provided in Table 5, which indicates the proper functioning of the model.

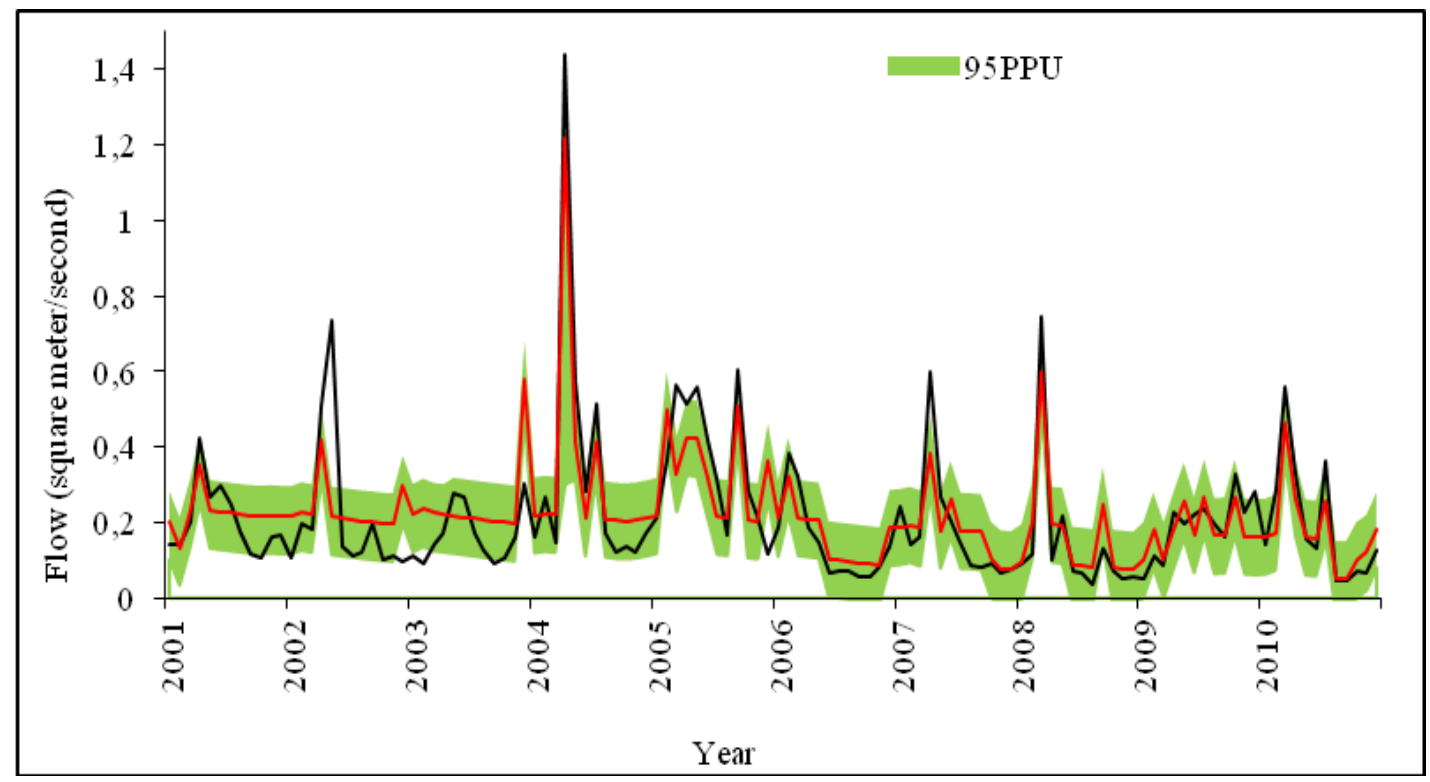

Figure 11. Simulated and observed values with the confidence interval for validation period

Table 5. Coefficients obtained in validation process model to simulate the monthly runoff at the base time

\begin{tabular}{c|c|c|c|c}
\hline R-factor & P-factor & RMSE & NS & $\mathbf{R}^{\mathbf{2}}$ \\
\hline 1.21 & 0.71 & 0.117 & 0.61 & 0.69 \\
\hline
\end{tabular}

After calculating average temperatures, minimum, maximum, radiation and precipitation, the effect of climate on Chehel-Chai basin was found. Then the model for the base period of continuous rainfall-runoff SWAT was calibrated and validated. In the next step to assess the impact of climate change on runoff was investigated. Given that situation in the future time series (under the impact of climate change) the objectives of this study was, therefore, to obtain the time series, daily meteorological parameters related to SWAT model was replaced in future and by applying the calibration parameters in the base period was predicted for time series period. River flow scenarios predicted values over AIB, A2 and B1 in the period 2011 to 2030 (Fig. 12), 2046-2065 (Fig. 13) and 2080-2099 (Fig. 14) is provided.

Variable rate long-term average for the base period (1982 to 2010) and future periods (2011 to 2030, 2046 to 2065 and 2080 to 2099) during climate scenarios SRA1B, SRA2 and SRB1 is presented in Table 6.

In all three scenarios the highest rate in the period 2080-2099 will occur in future periods, however, for future periods, during the period 2046-2065 all three scenarios rate less than two periods, 2011-2030 and 2080-2099. 


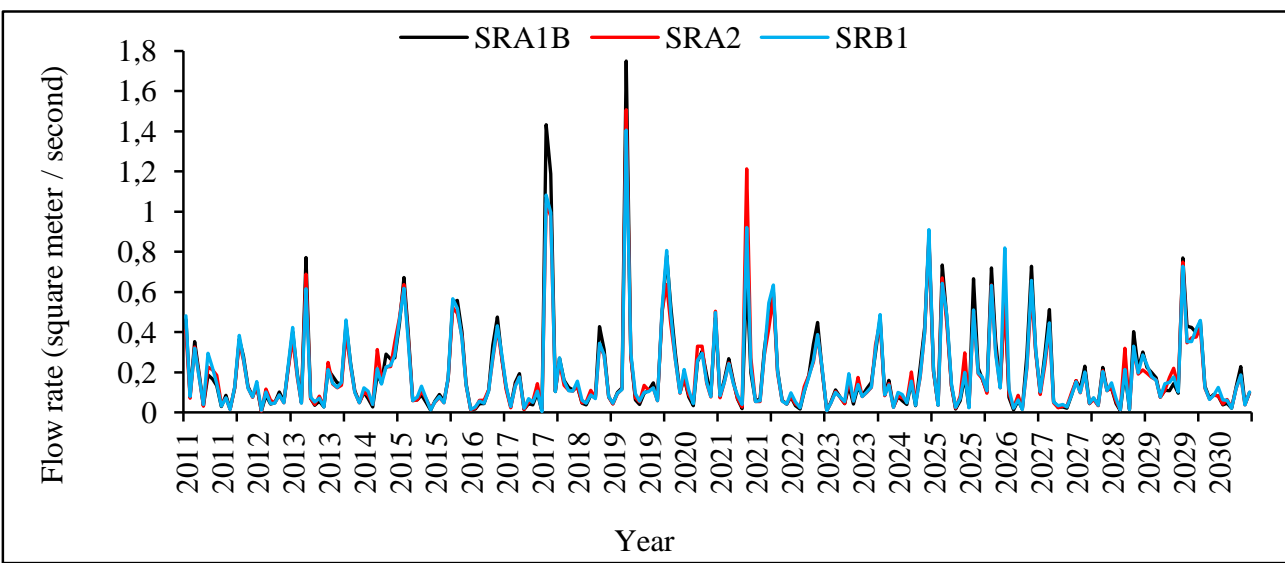

Figure 12. The predicted values river flows in Horizon 2020 (during 2011-2030) in scenarios $A I B, A 2$ and $B 1$

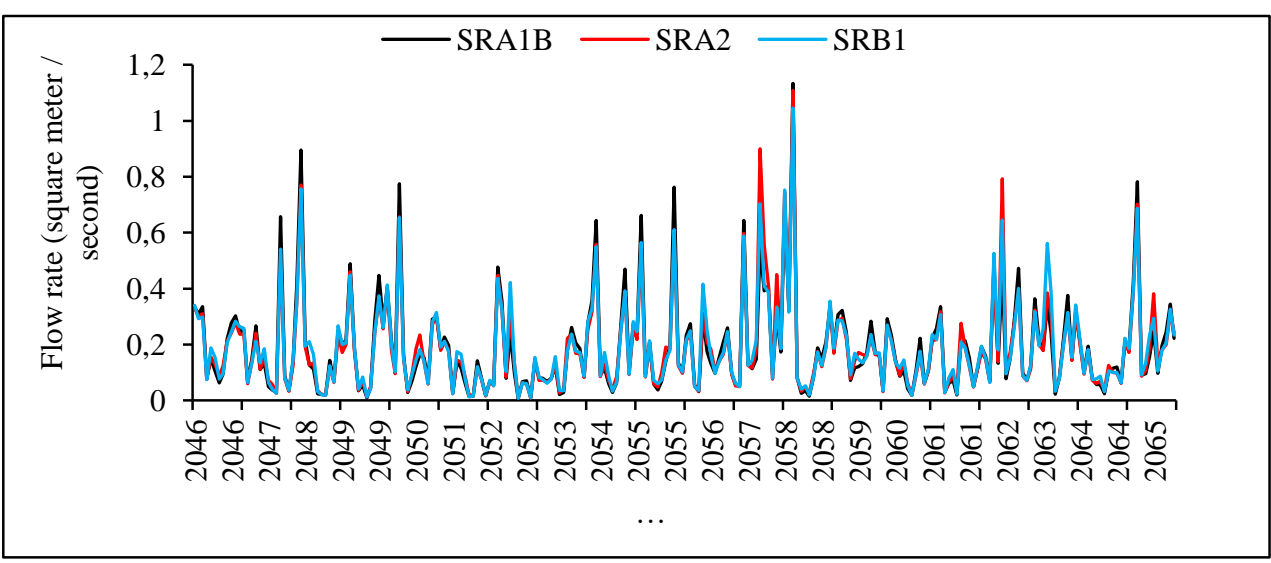

Figure 13. The predicted values river flows in Horizon 2055 (during 2046-2065) in scenarios $A I B, A 2$ and $B 1$

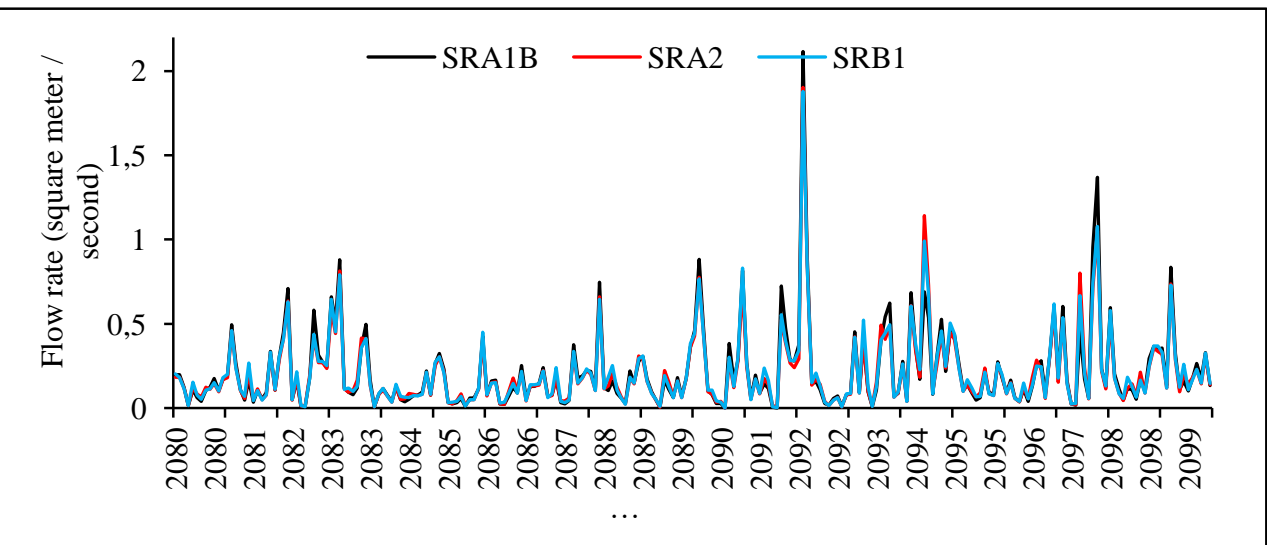

Figure 14. The predicted values river flows in Horizon 2090 (during 2080-2099) in scenarios $A I B, A 2$ and $B 1$ 
Table 6. Average long-term variable annual rate for the base period and future periods

\begin{tabular}{c|c|c}
\hline Long-term average of flow & Scenario & Period \\
\hline 0.339 & - & base \\
\hline 0.199 & SRA1B & \\
0.192 & SRA2 & $2011-2030$ \\
0.195 & SAB1 & \\
0.188 & SRA1B & \\
0.186 & SRA2 & $2046-2065$ \\
0.189 & SAB1 & \\
\hline 0.217 & SRA1B & \\
0.209 & SRA2 & $2080-2099$ \\
0.213 & SRB1 & \\
\hline
\end{tabular}

\section{Conclusion}

Assessment of climate change impacts on water resources is carried out in two steps. In the first step changes in temperature, rainfall was investigated in the second phase the change in runoff by SWAT model output step was carried out. Results are as follows:

- According to the approved model LARS-WG, climate change was for future periods from 2011 to 2030, 2046 to 2065 and 2080 to 2099 during climate scenarios SRA1B, SRA2 and SRB1 separately for variables minimum temperature, maximum temperature and precipitation. By comparing the values of the average minimum temperature is specified that the minimum temperature in all three rounds will be higher than the base period. $\left(0.31\right.$ to $0.70^{\circ} \mathrm{C}$ rise in temperature) In all three scenarios, the maximum temperature will occur at least in the period 2011-2030; however, for future periods, during the period 20462065 all three scenarios are lower than the minimum temperature two periods 2011-2030 and 2080-2099.

- By comparing the average values of maximum temperature, specified that the maximum temperature in all three rounds will be higher than the base period. (Rise in temperature to 0.82 degrees Celsius 0.37) In all three scenarios the highest maximum temperature will occur in 2011-2030 period; however, for future periods, during the period 2080-2099 all three scenarios are lower than the maximum temperature and will be two periods of 2011-2030 and 2046-2065. Overall results indicated that in future climate scenarios, rising temperatures will occur. In research Yu et al. (2002) also shows an increase in temperature results in prolonged periods of time and drastic changes in daily rainfall events is likely.

- Comparing the average values of rainfall, it was found that precipitation in all three rounds will be higher than the base period. (Increased precipitation between 2.34 to $35.89 \mathrm{~mm}$ ) and with rainfall amounts will increase over time. In all three scenarios, the most precipitation will occur over the period 2080-2099; however, for future periods, during the period 2011-2030 all three scenarios is less than two periods 2046-2065 and 2080-2099.

- After the initial login parameters SWAT model and its implementation, an analysis of the sensitivity of the effect of various parameters on model outputs, Nash-Sutcliffe based on the objective function has little effect in output 
parameters that have to be removed and only be used for model calibration and sensitivity parameters. As a result, the order of 10 parameters including number curve, soil evaporation coefficient, the coefficient $\alpha$ to save waterborne Channel coast, the rate of temperature change with height in the suburbs, the average temperature for the rain turning to snow, the temperature of melting snow, the rate of change of temperature with height, coefficient of penetration determination to deep aquifer and feeding percentage of deep groundwater from shallow aquifers showed the greatest sensitivity. These results clearly show that the number of curves that are associated with land use change, are most susceptible to runoff.

- After the calibration and validation of models based on super critical parameters, performance evaluation model using coefficients $\mathrm{R}^{2}$, NS, RMSE, P-factor and $\mathrm{R}$-factor between observed and data was simulated. The results in this section in calibration and validation step indicated that the model efficiency coefficient (Nash-Sutcliffe) was positive and correlation coefficient was greater than 0.6 and RMSE value was too low. Therefore, this model has a good ability to simulate water flow in the time period.

- Comparing the long-term average annual rate, it is clear that all three rates in the future will be less than the base period (reduction rate of 0.122 to 0.153 cubic meters per second). In all three scenarios the highest rate in the period 20802099 will occur in future periods, however, for future periods, during the period 2046-2065 all three scenarios rate less than two periods, 2011-2030 and 20802099. Varanou et al. (2003) research using the SWAT model observed that the current decline will occur in the future. Although research results (Ficklin et al., 2009) showed that the precipitation and evapotranspiration are decreased, but it seems to be the opposite of Chehel-Chai River basin. So that the results showed that temperature and precipitation and runoff is reduced. Despite the increased rainfall, rising temperatures will lead to increased evapotranspiration, which will lead to reduced flow in rivers. However, the issue of excessive exploitation from water sources can be known related.

\section{REFERENCE}

[1] Chen, J., Brissette, F. P., Leconte, R. (2011): Uncertainty of downscaling method in quantifying the impact of climate change on hydrology. - Journal of Hydrology 401(3-4): 190-202.

[2] Dhar, S., Mazumdar, A. (2009): Hydrological modelling of the Kangsabati river under changed climate scenario: case study in India. - Hydrological Processes 23 (16): 23942406.

[3] Ficklin, D. L., Luo, Y., Luedeling, E., Zhang, M. (2009): Climate change sensitivity assessment of a highly agricultural watershed using SWAT. - Journal of Hydrology 374 (1-2): 16-29.

[4] Gordon, C., Cooper, C., Senior, C. A., Banks, H., Gregory, J. M, Johns T. C, Mitchell, J. F. B, Wood, R. A. (2000): The simulation of SST, sea ice extents and ocean heat transports in a version of the Hadley Centre coupled model without flux adjustments. Clim. Dynam. 16: 147-168.

[5] Inouye, A. M., Lach, D. H., Stevenson, J. R., Bolte, J. P., Koch, J. (2017): Participatory Modeling to Assess Climate Impacts on Water Resources in the Big Wood Basin, Idaho. 
- Environmental Modeling with Stakeholders. Springer International Publishing, 289306.

[6] Intergovernmental Panel on Climate Change (IPCC) (2007): The physical science basis. Cambridge University Press, Cambridge.

[7] Koutroulis, A. G., Tsanis, I. K., Daliakopoulos, I. N., Jacob, D. (2013): Impact of climate change on water resources status: A case study for Crete Island, Greece. - Journal of Hydrology 479: 146-158.

[8] Lin, S. H., Liu, C. M., Huang, W. C., Lin, S. S., Yen, T. H., Wang, H. R., .Lee, Y. C: (2010): Developing a yearly warning index to assess the climatic impact on the water resources of Taiwan, a complex-terrain island. - Journal of hydrology 390(1): 13-22.

[9] Nepal, S. (2016): Impacts of climate change on the hydrological regime of the Koshi River basin in the Himalayan region. - Journal of Hydro-environment Research 10: 7689.

[10] Nkhonjera, G. K. (2017): Understanding the impact of climate change on the dwindling water resources of South Africa, focusing mainly on Olifants River basin: A review. Environmental Science \& Policy 71: 19-29.

[11] Pope, V. D., Gallani, M. L., Rowntree, P. R., Stratton, R. A. (2000): The impact of new physical parameterizations in the Hadley Centre climate model - HadAM3. - Climate Dynamics 16: 123-146.

[12] Seiller, G., Roy, R., Anctil, F. (2017): Influence of three common calibration metrics on the diagnosis of climate change impacts on water resources. - Journal of Hydrology 547: 280-295.

[13] Steele-Dunne, S., Lynch, P., McGrath, R., Semmler, T., Wang, S., Hanafin, J., Nolan, P. (2008): The impacts of climate change on hydrology in Ireland. - Journal of Hydrology 356(1): 28-45.

[14] Varanou, E., Pikounis, M., Baltas, E., Mimikou, M. (2003): Application of the SWAT model for the sensitivity analysis of runoff to land use change. - In 2003 International SWAT Conference (p. 89).

[15] Yu, P. S., Yang, T. C., Wu, C. K. (2002): Impact of climate change on water resources in southern Taiwan. - Journal of Hydrology 260(1): 161-175. 